\title{
Maternal late-gestation metabolic stress is associated with changes in immune and metabolic responses of dairy calves
}

\author{
Tahlia Ling, ${ }^{*}$ Marta Hernandez-Jover, ${ }^{*} \dagger$ Lorraine M. Sordillo, $\ddagger$ and Angel Abuelo* $†{ }^{1}$ \\ *School of Animal and Veterinary Sciences, Faculty of Science, Charles Sturt University, Boorooma Street, Wagga Wagga NSW 2678, Australia \\ †Graham Centre for Agricultural Innovation (Charles Sturt University and NSW Department of Primary Industries), Albert Pugsley Place, \\ Wagga Wagga NSW 2650, Australia \\ fDepartment of Large Animal Clinical Sciences, College of Veterinary Medicine, Michigan State University, East Lansing 48824
}

\begin{abstract}
Metabolic stress in periparturient dairy cows is characterized by excessive lipid mobilization, inflammation, and oxidative stress that is associated with immune dysfunction. Thus, metabolic stress around the time calving is linked to the development of various earlylactation health disorders. Maternal status during late pregnancy can have carryover effects on several health and production variables of neonatal calves. However, the effects of metabolic stress during gestation on metabolic and immune responses of newborn calves remain unknown. Thus, we aimed to investigate whether metabolic stress in late-gestation dairy cows is associated with changes in the metabolic and immune responses of their offspring during the first month of life. HolsteinFriesian cows $(\mathrm{n}=12)$ were blood sampled at 28 and $15 \mathrm{~d}$ before expected calving. The average between these 2 sampling points in the serum concentrations of nonesterified fatty acids (NEFA), haptoglobin (Hp), and oxidant status index (OSi) - defined as the ratio between reactive oxygen and nitrogen species and total antioxidant potential - were calculated as indicators of the degree of lipid mobilization, inflammation, and oxidant status (OS), respectively. Calves were subsequently divided into groups ( $\mathrm{n}=6$ each) according to their dams' high or low degree of lipid mobilization, inflammation, and OS. The metabolic responses of calves in each of these groups were compared weekly throughout their first month of life by assessing serum concentration of NEFA, Hp, and OSi. Additionally, whole blood was obtained from calves at each sampling period and subjected to a lipopolysaccharide (LPS)-stimulated tumor necrosis factor- $\alpha$ (TNF- $\alpha$ ) production assay to assess cell-mediated innate immunity against induced inflammatory responses, using high $(5 \mu \mathrm{g} / \mathrm{mL}$ of blood)
\end{abstract}

\footnotetext{
Received October 23, 2017.

Accepted March 20, 2018.

${ }^{1}$ Corresponding author: abuelo@msu.edu or angel.abuelo.sebio@ gmail.com
}

and low $(10 \mathrm{ng} / \mathrm{mL})$ concentrations of LPS. Calves born to cows with higher NEFA or OSi showed lower body weight at birth and throughout the study, whereas no association between any of the maternal groups and average daily gain at $4 \mathrm{wk}$ of age was identified. Serum concentrations of reactive oxygen and nitrogen species were higher in calves exposed to higher maternal NEFA concentrations or OSi when compared with calves born to cows with lower values of these biomarkers. Calves exposed to high maternal OS also had higher circulating concentrations of $\mathrm{Hp}$ and $\mathrm{TNF}-\alpha$, indicating greater basal inflammatory responses when compared with calves born to cows with a lower OSi. In contrast, LPS-induced inflammatory responses were less robust in calves exposed to higher maternal biomarkers of inflammation or OS, suggesting compromised immune responses to microbial agonists. Collectively, these data suggest that prenatal exposure to maternal parameters of metabolic stress may adversely affect some metabolic and inflammatory responses of the offspring that could influence disease susceptibility.

Key words: calf health, dairy cow, lipid mobilization, oxidative stress, transition period

\section{INTRODUCTION}

Dairy cows experience metabolic stress during the transition period when they fail to physiologically adapt to the profound increase in nutrient requirements associated with fetal growth and milk production (Sordillo and Mavangira, 2014). Metabolic stress is characterized by excessive lipid mobilization, oxidative stress, and inflammatory dysfunction (Abuelo et al., 2015). The negative effect of metabolic stress on the immune function, health, and production of dairy cattle during this period is well established (Kehrli et al., 1989; Sordillo and Aitken, 2009). Metabolic stress starts several weeks before calving (Grummer, 1993; Sordillo and Raphael, 2013), and therefore can potentially affect the fetus.

Evidence exists in other nonruminant species that maternal stress during gestation influences fetal devel- 
opment and exerts carryover effects on the offspring (McMillen and Robinson, 2005; Merlot et al., 2008). Studies in humans and murine models demonstrated that suboptimal intrauterine conditions during critical periods of development lead to changes in tissue structure and function (Fowden et al., 2006), which may have long-term consequences on offspring physiology and disease susceptibility (McMillen and Robinson, 2005; Merlot et al., 2008). Studies in dairy cattle have also demonstrated that exposure to heat stress and restricted or excessive energy intake during late gestation affect the immune and metabolic function of the offspring (Gao et al., 2012; Tao et al., 2012, 2014; Osorio et al., 2013). Moreover, Monteiro et al. (2016) demonstrated that the detrimental effects of in utero exposure to heat stress on milk yield and reproductive performance extend to at least the first lactation of offspring. Thus, prenatal conditions have the potential of significantly affecting the productivity and health status of replacement heifers.

The first month of life is a time when the greatest neonatal morbidity and mortality rates are observed on dairy farms (Windeyer et al., 2014); hence, maternal carryover effects can have a significant effect on calf health during this time. Unfortunately, no information exists on how metabolic stress in the dam can affect immune responses in the newborn calf when they are at risk for succumbing to health disorders. Therefore, we hypothesized that calves born to cows experiencing increased metabolic stress will exhibit altered metabolic status and immune responses in the first month of life. The objective of our preliminary observational study was to compare metabolic status and LPS-induced whole blood tumor necrosis factor- $\alpha$ (TNF- $\alpha$ ) release between calves born to cows that experienced different degrees of maternal metabolic stress. As an index for quantification of metabolic stress is yet to be established (Sordillo and Mavangira, 2014; Abuelo et al., 2015), the carryover effects of the 3 components of metabolic stress triad (lipid mobilization, inflammation, and oxidative stress) were separately assessed.

\section{MATERIALS AND METHODS}

\section{Animals}

The Charles Sturt University Animal Care and Ethics Committee approved all procedures involving animals before the commencement of the study (Protocol 15/120). During October and November 2016, 12 multiparous Holstein-Friesian dairy cows and their calves were monitored for the last month of gestation and the first month of life, respectively. Given the lack of previous studies investigating the effect of maternal metabolic stress on the calves immune and metabolic status, this sample size was selected to create 2 groups $(n=6)$ for comparison. Cows entering their 2nd to 4th lactation were selected based on the proximity of their calving dates from a 180-head commercial pasturebased dairy farm located in Ladysmith, New South Wales, Australia, with an average 305-d normalized milk production of $8,513 \mathrm{~kg} / \mathrm{cow}$.

Further selection criteria included a variation in BCS lower or equal to 0.5 points during the last month of gestation for cows and adequate passive transfer of immunoglobulins in the calves. For this, cows were body condition scored to the nearest quarter point using the 5 -point $(1=$ lean, $5=$ obese $)$ system described by Edmonson et al. (1989) at each sampling point and within the first week after calving. To assess passive transfer of immunity, the serum sample collected in the first week of age was analyzed for IgG using a radioimmunodiffusion assay (Bovine IgG test, Triple J Farms, Bellingham, WA). The first 12 cow/calf pairs met both criteria, with all calves being singletons born from an unassisted eutotic calving and having an IgG concentration higher than the $10 \mathrm{~g} / \mathrm{L}$ cutoff commonly used to define failure of passive transfer of immunity (Godden, 2008). Hence, no further animals were enrolled. Additionally, all animals underwent a weekly veterinary clinical exam throughout the study period to rule out any clinical disease. In calves, the exam included assessment of appetite, rectal temperature, heart and respiratory rate, umbilical and joint swelling, and the presence or absence of diarrhea. None of the animals enrolled in the study showed clinical signs of disease; hence, the data from all cows and calves was included in the statistical analyses. Calf weights were estimated with a heart girth tape (Holstein Calf Weigh Tape; The Coburn Company Inc., Whitewater, WI) placed vertically at the point of the elbow (Heinrichs et al., 2007).

Cows and calves in the study were each managed under identical conditions. Cows were housed outdoors on pasture, and calves were housed in individual calf shelters for the first $2 \mathrm{wk}$ of life and then housed in a straw-bedded shed in groups of 6 to 8 calves. Cows were dried off $60 \mathrm{~d}$ before the expected calving date. During the first 4 wk of the dry period, cows grazed a ryegrass and clover pasture with an estimated supply of $2.5 \mathrm{~kg}$ of DM/d per cow and were offered oaten hay ad libitum. For the last $30 \mathrm{~d}$ of the dry period, cows received $2 \mathrm{~kg}$ of concentrate and $1 \mathrm{~kg}$ of anion salts once daily in addition to the same supply of pasture and ad libitum access to oaten hay. Calves were removed from dams within $12 \mathrm{~h}$ after birth. Calves received $4 \mathrm{~L}$ of colostrum from their respective dams within the first $12 \mathrm{~h}$ of life and then twice daily for the first $2 \mathrm{~d}$ at a rate of $10 \% \mathrm{BW} / \mathrm{d}$. Thereafter, they received $2.5 \mathrm{~L}$ of 
unpasteurized whole milk every $12 \mathrm{~h}$ until the end of the study period. After the first week of age, calves had ad libitum access to Lucerne hay and a commercial calf pelletized concentrate (Veanavite No. 2 Calf Pellets, Rivalea Australia Pty Ltd., Corowa, NSW, Australia). The chemical composition of the feedstuffs given to cows and calves is presented in Supplemental Tables S1 and S2 (https://doi.org/10.3168/jds.2017-14038).

\section{Sample Collection}

Blood samples from cows were collected via coccygeal venipuncture at 28 and $15 \mathrm{~d}$ before the expected calving date $(23 \pm 1.8$ and $11 \pm 1.6 \mathrm{~d}$ before actual calving date; mean $\pm \mathrm{SD}$ ). Calves were blood sampled via jugular venipuncture weekly for the first month of life $(7 \pm 0.8,14 \pm 1.0,20 \pm 0.8$, and $29 \pm 0.8 \mathrm{~d}$ of age). Sampling time was kept consistent throughout the study, with cows being sampled $1 \mathrm{~h}$ before the administration of concentrate and anion salts, and calves $3 \mathrm{~h}$ after the morning milk feeding. Blood was collected into plain vacuum tubes (BD Vacutainer; Becton, Dickinson and Company, Plymouth, UK) from cows and calves. Blood was allowed to clot at room temperature and sera were subsequently harvested after centrifugation at $2,000 \times g$ for $20 \mathrm{~min}$ at $4^{\circ} \mathrm{C}$, aliquoted, and stored at $-20^{\circ} \mathrm{C}$ pending analysis within 3 mo of collection. Three 9-mL EDTA vacuum tubes (Vacuette K3EDTA; Greiner Bio-One GmbH, Kremsmünster, Austria) were also collected from each calf, immediately stored on crushed ice, and transported to the laboratory.

\section{Analytical Determinations}

Haptoglobin (Hp) was determined as a biomarker of inflammation, whereas the concentration of nonesterified fatty acids (NEFA) was employed to indicate the degree of lipid mobilization. Commercially available assays were used to determine serum NEFA (Wako NEFA Assay, Wako Diagnostics, Mountain View, CA) and Hp (Phase Haptoglobin Assay TP-801, Tridelta Development Limited, Maynooth, Ireland) concentrations, following the manufacturer's instructions (http://www .trideltaltd.com/includes/tng/pub/tNG_download4 .php?LINK=haptoglobin-main-page\&KT_download1 $=191122 \mathrm{c} 2263 \mathrm{dd} 494980 \mathrm{e} 70 \mathrm{~d} 3 \mathrm{f} 8 \mathrm{ff} 938 \mathrm{f}$.) The EDTAcollected blood was submitted to the Charles Sturt University Veterinary Diagnostic Laboratory (Wagga Wagga, NSW, Australia) for differential blood cell counting using a Cell Dyn 3500 automated hematology analyzer (Abbott Diagnostics, Lake Forest IL).

Oxidant status (OS) was assessed as previously described (Abuelo et al., 2016). A commercially available fluorometric assay (OxiSelect In Vitro ROS/RNS As- say Kit; Cell Biolabs Inc., San Diego, CA) was used following the manufacturer's instructions (https://www .cellbiolabs.com/sites/default/files/STA-347-in-vitro -ros-rns-assay-kit.pdf) to measure reactive oxygen and nitrogen species (RONS) in serum as a marker of oxidant production. In brief, a specific probe was added to and reacted with free radicals within the sample, yielding a fluorescent product. Fluorescence of the dichlorofluorescent dye was measured at $480 \mathrm{~nm}$ of excitation and $530 \mathrm{~nm}$ of emission. The fluorescence of blank samples was subtracted from sample measurements to eliminate background fluorescence. A standard dichlorofluorescent dye curve was included to ensure that the dye could be detected at various concentrations. The reported values represent relative fluorescent units normalized per microliter of sample.

The serum antioxidant potential (AOP) was measured using the Trolox equivalent antioxidant capacity, as previously described (Re et al., 1999). Briefly, the AOP of a sample was expressed as the equivalence of a known Trolox (synthetic vitamin E analog) standard (Sigma Aldrich, St. Louis, MO) concentration, resulting in a similar reduction of the generated radical 2,2'-azino-bis-3-ethylbenzothiazoline-6-sulfonic acid (Sigma Aldrich) determined using the standard curve. Both parameters of the redox balance were assessed together as the ratio of pro-oxidant to total antioxidant defenses (RONS/AOP), namely oxidant status index (OSi), as it accurately detects changes in oxidant status during the transition period (Abuelo et al., 2013). An increase in the ratio indicates a higher risk for oxidative stress due to an increase in pro-oxidant production or defensive antioxidant depletion.

\section{LPS Stimulation of Whole Blood}

At weekly intervals during the first month of life, calf' EDTA blood samples were subjected to an ex vivo cytokine release assay to estimate the innate immunologic response to external stimuli (Damsgaard et al., 2009). Stimulation of the whole blood samples with LPS (Escherichia coli 0111:B4, Sigma Aldrich) was performed within $2 \mathrm{~h}$ of collection, as described previously (O'Boyle et al., 2006) with slight modifications. Briefly, the 3 EDTA tubes collected from the same calf were mixed, and three 5 -mL aliquots were stimulated for $3.5 \mathrm{~h}$ at $37{ }^{\circ} \mathrm{C}$ with a high $(5 \mu \mathrm{g} / \mathrm{mL}$ of blood) or low (10 ng/mL of blood) concentration of LPS or endotoxin-free Dulbecco's Modified Eagle Medium (Sigma Aldrich) as a negative control. Blood was handled in sterile, pyrogen-free, tubes (SuperClear Centrifuge Tubes; Labcon, Petaluma, CA). Following incubation, samples were centrifuged at $1,300 \times$ $g$ for $10 \mathrm{~min}$ at $4^{\circ} \mathrm{C}$. Plasma samples were collected 
on crushed ice, stored at $-80^{\circ} \mathrm{C}$, and assayed in duplicate for TNF- $\alpha$ concentrations using a bovine-specific ELISA assay (Bovine TNFo ELISA; Thermo Scientific, Waltham, MA) with a detection limit of $0.1 \mathrm{ng} / \mathrm{mL}$. The intra- and interassay coefficients of variation were 6.2 and $9.4 \%$, respectively.

\section{Statistical Analysis}

The average between the 2 sampling points of the dams was calculated for the serum $\mathrm{Hp}$ (marker of inflammation) and NEFA (marker of lipid mobilization) concentrations and OSi (marker of OS). The offspring of cows with a mean below and above the median for each of the above variables were placed in low $(\mathrm{n}=$ $6)$ and high $(\mathrm{n}=6)$ groups, respectively. All statistical analyses were performed with SPSS Statistics for Windows version 20.0 software (IBM Corp., Armonk, NY). The Mann-Whitney U-test was used to compare adult cow data between groups and correlation analyses among adult cattle variables were performed with the Spearman's test. Generalized linear mixed models with repeated measures were built for the calf variables BW, NEFA, Hp, RONS, AOP, OSi, basal TNF- $\alpha$ concentration, TNF- $\alpha$ concentration following $10 \mathrm{ng} / \mathrm{mL}$ of LPS stimulation, TNF- $\alpha$ concentration following 5 $\mu \mathrm{g} / \mathrm{mL}$ of LPS stimulation, TNF- $\alpha$ percentage increase from basal concentration following 10 and $5 \mu \mathrm{g} / \mathrm{mL}$ of LPS stimulation, and the different blood cells populations (total leukocytes, neutrophils, lymphocytes, monocytes, eosinophils, and basophils). Fixed effects included the sampling week $(1,2,3$, or 4$)$, calf groups (high/low) of maternal NEFA, maternal Hp, and maternal $\mathrm{OSi}$, as well as the different time $\times$ group inter- actions. Calf identification was the random effect. For repeated measures, 5 covariance structures were tested (unstructured, autoregressive 1, variance components, compound symmetry, and Toeplitz), and the 1 resulting in the lowest Akaike information criterion was chosen. The degrees of freedom were approximated with the Kenward-Roger method. Model assumptions were assessed by evaluation of homoscedasticity and normality of residuals. To satisfy this assumption, data of NEFA and RONS were natural log-transformed and resulting least squares means estimates were subsequently back transformed and presented as the geometric mean. Similar models without repeated measures were built for the variables birth weight and ADG. These models included the different calf groups as fixed effects and calf sex as random effect. All $P$-values given are those controlled for multiple comparisons with Bonferroni's test. Statistical significance was declared at $P<0.05$.

\section{RESULTS}

The mean (SD) concentration of the cow biomarkers is presented by group and sampling point in Table 1. Only the classifying variables differed significantly between the low and high groups of each biomarker. Similarly, no strong or significant correlations were identified among maternal variables apart from the ones between the $\mathrm{OSi}$ and its constituent variables RONS and AOP (Table 2).

Regarding the offspring, high maternal lipid mobilization during late gestation was associated with significantly higher serum OSi and Hp in the calves (Table 3). In addition, calves born to cows with a higher OSi during late gestation had a significantly higher serum

Table 1. Mean (SD) of the maternal variables categorized by group and sampling point ${ }^{1}$

\begin{tabular}{|c|c|c|c|c|c|c|c|}
\hline \multirow{2}{*}{$\begin{array}{l}\text { Maternal } \\
\text { variable }\end{array}$} & \multirow{2}{*}{$\begin{array}{l}\text { Days before } \\
\text { expected } \\
\text { calving }\end{array}$} & \multicolumn{6}{|c|}{ Group } \\
\hline & & \multicolumn{2}{|c|}{ NEFA } & \multicolumn{2}{|c|}{$\mathrm{Hp}$} & \multicolumn{2}{|c|}{ OSi } \\
\hline \multirow[t]{2}{*}{$\overline{\mathrm{BCS}}$} & 28 & $3.0(0.36)$ & $3.0(0.41)$ & $3.2(0.14)$ & $2.9(0.15)$ & $3.2(0.25)$ & $3.0(0.51)$ \\
\hline & 15 & $3.1(0.31)$ & $3.1(0.41)$ & $3.2(0.31)$ & $3.1(0.32)$ & $3.1(0.34)$ & $3.2(0.37)$ \\
\hline $\begin{array}{l}\mathrm{NEFA} \\
(\mathrm{mmol} / \mathrm{L})\end{array}$ & 28 & $0.20(0.037)$ & $0.35(0.099)^{*}$ & $0.26(0.101)$ & $0.28(0.116)$ & $0.24(0.106)$ & $0.31(0.126)$ \\
\hline $\mathrm{Hp}(\mathrm{g} / \mathrm{L})$ & 15 & $0.24(0.186)$ & $0.18(0.098)$ & $0.12(0.033)$ & $0.29(0.182)^{*}$ & $0.16(0.094)$ & $0.28(0.184)$ \\
\hline \multirow{2}{*}{$\begin{array}{l}\text { RONS } \\
(\mathrm{RFU} / \mu \mathrm{L})\end{array}$} & 28 & $32.6(5.84)$ & $32.6(3.88)$ & $30.9(5.05)$ & $34.3(4.76)$ & $23.1(3.52)$ & $42.2(5.43)^{*}$ \\
\hline & 15 & $33.5(5.73)$ & $28.8(3.58)$ & $32.5(4.55)$ & $29.7(5.14)$ & $26.5(4.57)$ & $45.8(4.30)^{*}$ \\
\hline \multirow{2}{*}{$\begin{array}{l}\mathrm{AOP} \\
(\mu M)\end{array}$} & 28 & $39.3(4.52)$ & $40.5(5.36)$ & $34.7(5.08)$ & $45.16(4.83)$ & $40.1(4.19)$ & $38.9(7.53)$ \\
\hline & 15 & $38.9(3.06)$ & $41.7(4.18)$ & $40.2(4.09)$ & $44.9(3.64)$ & $44.7(4.47)$ & $40.4(3.23)$ \\
\hline \multirow{2}{*}{$\begin{array}{l}\text { OSi } \\
\text { (arbitrary units) }\end{array}$} & 28 & $0.81(0.274)$ & $0.89(0.16)$ & $0.93(0.144)$ & $0.78(0.126)$ & $0.58(0.104)$ & $1.20(0.127)^{* *}$ \\
\hline & 15 & $0.87(0.154)$ & $0.75(0.25)$ & $0.83(0.123)$ & $0.70(0.149)$ & $0.67(0.122)$ & $0.98(0.166)^{*}$ \\
\hline
\end{tabular}

\footnotetext{
${ }^{1}$ At each sampling point, groups were compared statistically with the Mann-Whitney $U$-test. NEFA = nonesterified fatty acids; Hp $=$ haptoglobin; RONS $=$ reactive oxygen and nitrogen species; RFU $=$ relative fluorescence units; $\mathrm{AOP}=$ antioxidant potential; OSi $=$ oxidant status index . ${ }^{*} P<0.05 ; * * P<0.01$.
} 
Table 2. Correlation analyses among maternal biomarkers of metabolic stress (shown as Spearman $\rho$ correlation coefficient $)^{1}$

\begin{tabular}{lccccc}
\hline Variable & NEFA & Hp & RONS & AOP & OSi \\
\hline NEFA & - & 0.105 & 0.007 & 0.130 & -0.04 \\
Hp & 0.105 & - & 0.062 & -0.034 & 0.07 \\
RONS & 0.007 & 0.062 & - & 0.104 & $0.75^{* *}$ \\
AOP & 0.130 & -0.034 & 0.104 & - & $-0.58^{* *}$ \\
OSi & -0.04 & 0.07 & $0.75^{* *}$ & $-0.58^{* *}$ & - \\
\hline
\end{tabular}

${ }^{1} \mathrm{NEFA}=$ nonesterified fatty acids; $\mathrm{Hp}=$ haptoglobin; RONS $=$ reactive oxygen and nitrogen species; $\mathrm{AOP}=$ antioxidant potential; $\mathrm{OSi}=$ oxidant status index.

${ }^{*} P<0.05 ; * * P<0.01$.

concentration of RONS and Hp. Calves born to cows with higher NEFA or OSi showed significantly lower BW at birth and throughout the study period, whereas no association between any of the maternal metabolic stress groups and ADG at 4 wk of age was identified (Table 4; Figure 1). No differences were observed in the differential blood count results between low and high groups of any of the studied variables (Table 5).

Exposure to higher OSi during late gestation was associated with higher basal concentrations of TNF- $\alpha$, as well as significantly higher TNF- $\alpha$ plasma concentrations after stimulation with either $10 \mathrm{ng} / \mathrm{mL}$ or 5 $\mu \mathrm{g}$ of LPS (Tables 6 and 7). Conversely, calves born to cows with a higher serum Hp concentration during late gestation showed a lower TNF- $\alpha$ plasma concentration after stimulation with either LPS concentrations (Tables 6 and 8). The responses in TNF- $\alpha$ concentration observed were proportional to the concentration of LPS used for the stimulation. When the TNF- $\alpha$ response following LPS-stimulation was quantified as the percentage increased from the basal TNF- $\alpha$ concentration, calves born to cows that suffered higher OS or inflammation showed a lower fold increase in TNF- $\alpha$ after LPS stimulation (Figure 2).

\section{DISCUSSION}

We estimated the in utero exposure to metabolic stress during the last month of gestation because this is the time when periparturient immunosuppression starts (Goff and Horst, 1997; Nonnecke et al., 2003), concurrently with the fastest proliferation of immune cells in the bovine fetuses (Higgins et al., 1983). For this, we measured biomarkers of the 3 components of the metabolic stress triad (Abuelo et al., 2015) in the dam's serum and classified their offspring according to the degrees of maternal lipid mobilization, inflammation, and OS experienced. The lack of correlation among the maternal biomarkers (Table 2) demonstrated the independency of each biomarker.

Calves exposed to high maternal lipid mobilization during late gestation had a significantly higher serum OSi and Hp concentrations. To our knowledge, the effect of maternal NEFA concentration during late ges-

Table 3. Least squares means of the offspring sera biomarkers of oxidant status, lipomobilization, and inflammation according to the degree of maternal stress experienced in late gestation ${ }^{1}$

\begin{tabular}{|c|c|c|c|c|c|c|c|c|c|c|c|c|c|c|}
\hline \multirow[b]{2}{*}{ Variable } & \multicolumn{2}{|c|}{ Maternal NEFA } & \multicolumn{2}{|c|}{ Maternal Hp } & \multicolumn{2}{|c|}{ Maternal OSi } & \multirow[b]{2}{*}{ SE } & \multicolumn{7}{|c|}{$P$-value } \\
\hline & $\begin{array}{c}\text { Low } \\
(\mathrm{n}=6)\end{array}$ & $\begin{array}{l}\text { High } \\
(\mathrm{n}=6)\end{array}$ & $\begin{array}{c}\text { Low } \\
(\mathrm{n}=6)\end{array}$ & $\begin{array}{l}\text { High } \\
(\mathrm{n}=6)\end{array}$ & $\begin{array}{c}\text { Low } \\
(\mathrm{n}=6)\end{array}$ & $\begin{array}{l}\text { High } \\
(\mathrm{n}=6)\end{array}$ & & NEFA & $\mathrm{Hp}$ & OSi & Time & NEFA & $\mathrm{Hp}$ & OSi \\
\hline $\begin{array}{l}\mathrm{NEFA} \\
(\mathrm{mmol} / \mathrm{L})\end{array}$ & 0.19 & 0.16 & 0.18 & 0.17 & 0.15 & 0.19 & 0.026 & 0.35 & 0.90 & 0.35 & 0.12 & 0.42 & 0.47 & 0.76 \\
\hline $\begin{array}{l}\text { RONS } \\
(\mathrm{RFU} / \mu \mathrm{L})\end{array}$ & 22.3 & 16.8 & 18.7 & 20.4 & 15.0 & $24.1^{*}$ & 2.20 & 0.19 & 0.68 & 0.041 & 0.24 & 0.67 & 0.67 & 0.22 \\
\hline $\begin{array}{l}\mathrm{AOP} \\
(\mu M)\end{array}$ & 44.8 & 38.3 & 45.8 & 37.3 & 40.0 & 43.2 & 5.09 & 0.41 & 0.29 & 0.68 & 0.14 & 0.09 & 0.48 & 0.75 \\
\hline OSi & 0.24 & $0.78^{*}$ & 0.43 & 0.59 & 0.42 & 0.61 & 0.091 & 0.026 & 0.27 & 0.062 & 0.044 & 0.08 & 0.39 & 0.054 \\
\hline
\end{tabular}

${ }^{1} \mathrm{NEFA}=$ nonesterified fatty acids; $\mathrm{Hp}=$ haptoglobin; RONS = reactive oxygen and nitrogen species; RFU = relative fluorescence units; AOP $=$ antioxidant potential; $\mathrm{OSi}=$ oxidant status index.

$* P<0.05$ compared with the low group. 
Table 4. Least squares means of the offspring birth weight and ADG during the first 4 wk of life according to the degree of maternal stress experienced in late gestation ${ }^{1}$

\begin{tabular}{|c|c|c|c|c|c|c|c|c|c|c|}
\hline \multirow{2}{*}{ Variable } & \multirow{2}{*}{\multicolumn{2}{|c|}{ Maternal NEFA }} & \multirow{2}{*}{\multicolumn{2}{|c|}{ Maternal Hp }} & \multirow{2}{*}{\multicolumn{2}{|c|}{ Maternal OSi }} & \multirow{2}{*}{$\mathrm{SE}$} & \multicolumn{3}{|c|}{$P$-value } \\
\hline & & & & & & & & \multicolumn{3}{|c|}{ Maternal groups } \\
\hline Birth weight (kg) & 40.6 & $38.7^{*}$ & 40.1 & 39.2 & 40.5 & $39.0^{*}$ & 0.52 & 0.040 & 0.24 & 0.045 \\
\hline ADG $(\mathrm{kg} / \mathrm{d})$ & 0.61 & 0.58 & 0.59 & 0.57 & 0.60 & 0.56 & 0.018 & 0.24 & 0.75 & 0.12 \\
\hline
\end{tabular}

${ }^{1}$ Generalized linear mixed models were built for the variables birth weight and ADG with the fixed effects of the calf groups and the random effect of calf sex. NEFA = nonesterified fatty acids; $\mathrm{Hp}=$ haptoglobin; OSi = oxidant status index.

${ }^{*} P<0.05$ compared with the low group.

tation on the oxidant and inflammatory status of the offspring in postnatal life has not yet been investigated. The mechanism by which prenatal exposure to high maternal NEFA concentrations in late gestation can be associated with an elevated OSi is unknown. However, in vitro studies demonstrate that fatty acids may induce cellular RONS production directly (Inoguchi et al., 2000; Listenberger et al., 2001) and indirectly by stimulating inflammatory pathways (Ohtsu et al., 2017). Furthermore, in vitro studies in bovine oocytes and blastocysts demonstrate that elevated NEFA concentrations alter gene expression related to oxidative metabolism (Van Hoeck et al., 2013, 2015). Osorio et al. (2013) did not find changes in the expression of some genes related to redox and inflammation homeostasis in PMNL of calves from dams fed prepartum diets differing in energy content. However, it is yet to be determined whether prenatal exposure to higher maternal NEFA concentrations during late gestation influences the expression of such genes. Further research is required to determine whether offspring exposed to high maternal NEFA concentrations during late gestation are at increased risk of diseases associated with oxidative stress and inflammation, such as diarrhea, pneumonia, and mastitis (Ranjan et al., 2006; Lykkesfeldt and Svendsen, 2007), later in life.

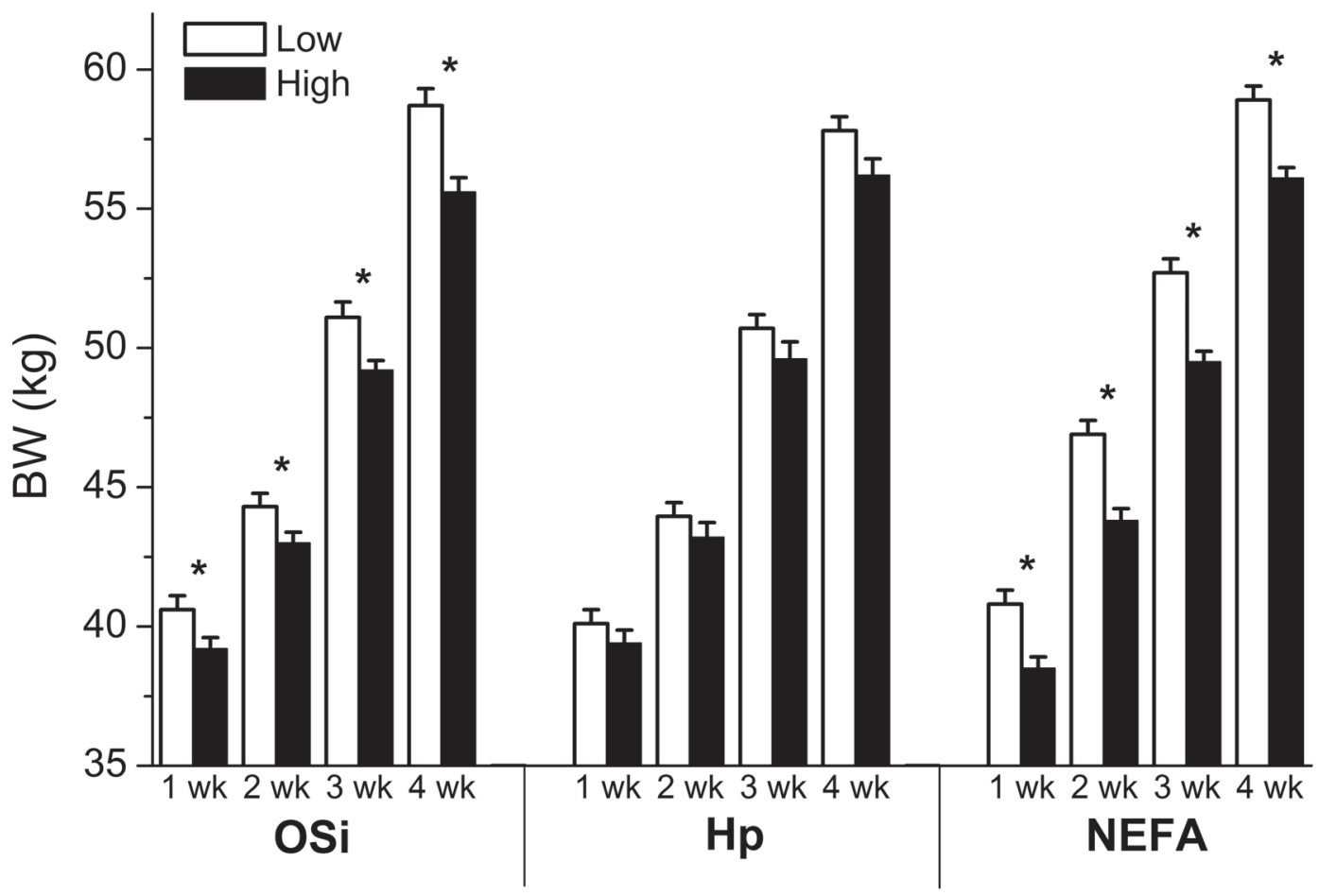

Figure 1. Body weight of the calves throughout the first $4 \mathrm{wk}$ of age according to the degree of maternal oxidant status, inflammation, or lipid mobilization during late gestation. Results expressed as LSM \pm SE. OSi = oxidant status index; Hp = haptoglobin; NEFA = nonesterified fatty acids. ${ }^{*} P<0.05$. 
Maternal OS during late gestation was positively associated with the serum concentration of RONS in the offspring. However, it was not associated with differences in their serum AOP or OSi. Antioxidants are produced endogenously and supplied by the diet (Abuelo et al., 2015). Thus, it is possible that the supply of diet-derived antioxidants was sufficient to offset the higher serum RONS concentration in calves exposed to higher maternal OS during late gestation. As the OS is determined by the ratio of oxidants to antioxi- dants, the clinical significance of an elevated level of RONS in the absence of an increased OSi is unknown. Given the small sample size of the current study, these results cannot rule out a positive relationship between maternal OS during gestation and the offspring's OSi in postnatal life. Nonetheless, the elevated OS observed in calves may have contributed to their diminished immune responsiveness and elevated level of basal inflammation, as oxidative stress may lead to immune and inflammatory dysfunction (Sordillo and Mavangira,

Table 5. Least squares means of the calves' white blood cell differential counts $\left(10^{9}\right.$ cells/L) according to week of age and group ${ }^{1}$

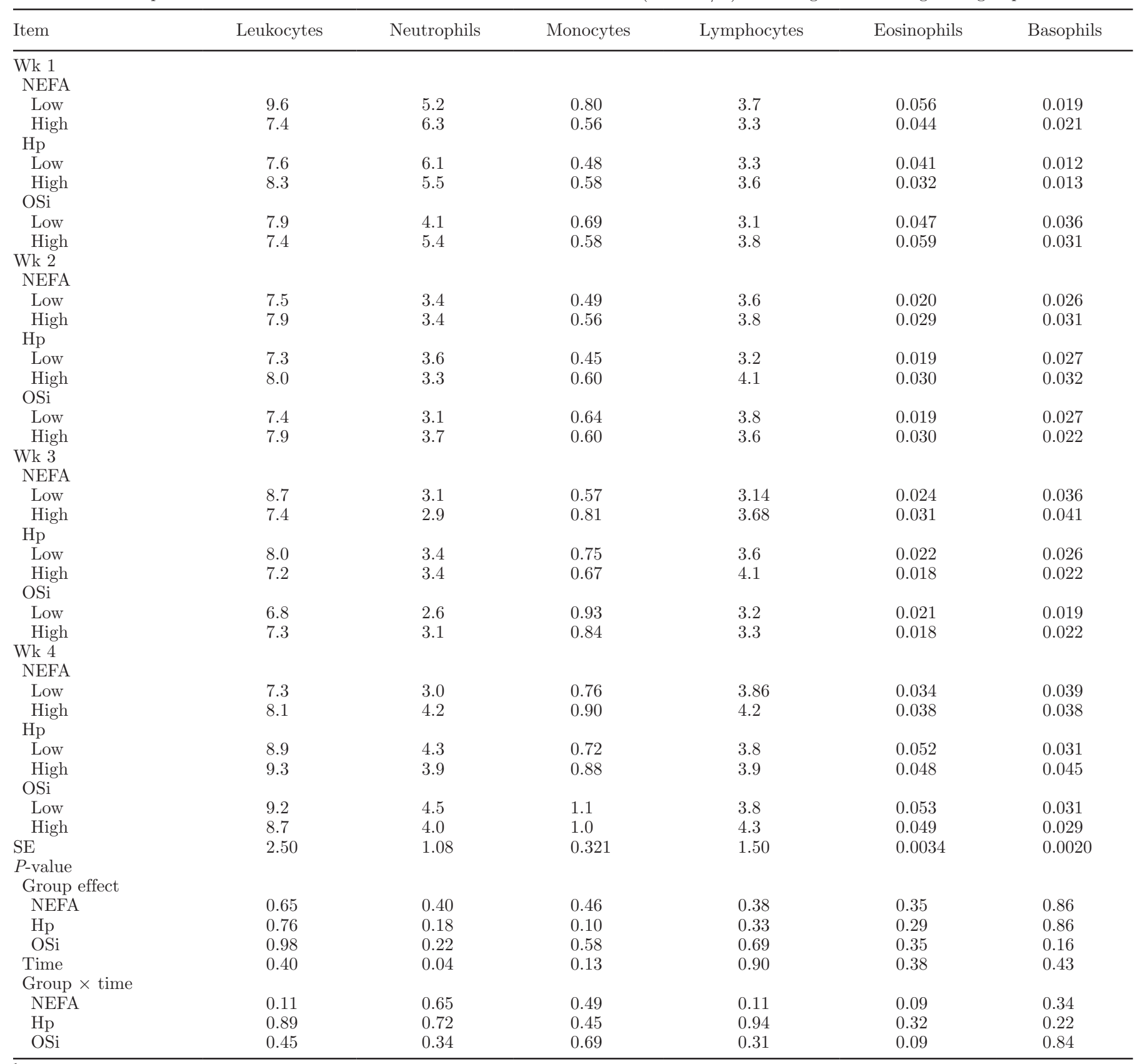

${ }^{1} \mathrm{NEFA}=$ nonesterified fatty acids; Hp = haptoglobin; OSi = oxidant status index. Each group (low or high) was composed of 6 calves. 
Table 6. Least squares means of offspring tumor necrosis factor (TNF)- $\alpha$ plasma concentration (ng/mL) after LPS stimulation for the first 4 wk of life according to the degree of maternal NEFA, Hp, and OSi during late gestation ${ }^{1}$

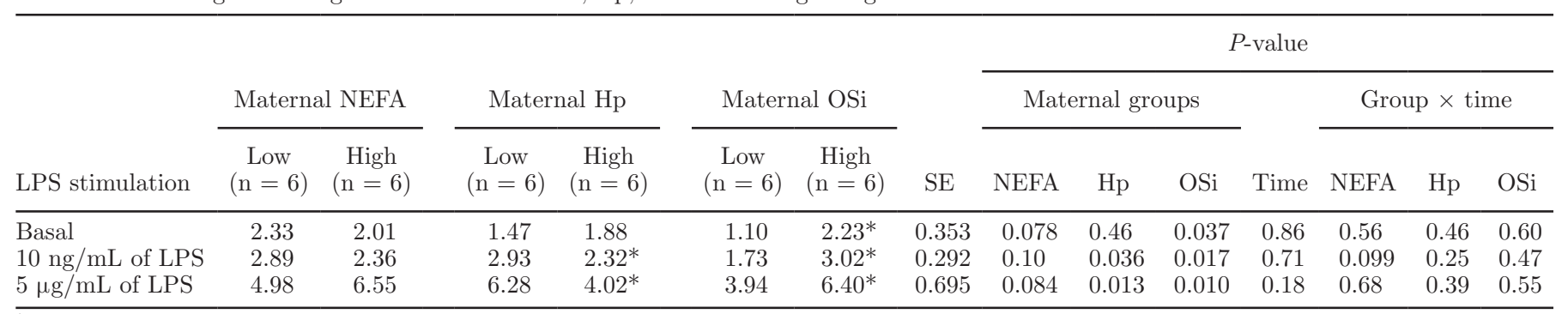

${ }^{1} \mathrm{NEFA}=$ nonesterified fatty acids; $\mathrm{Hp}=$ haptoglobin; $\mathrm{OSi}=$ oxidant status index.

${ }^{*} P<0.05$ compared with the low group.

2014). Further research is required to determine the clinical effect of OS during the first months of life. This is of particular interest because oxidative stress is involved in the pathogenesis of prevalent diseases that affect dairy calves, such as diarrhea and pneumonia (Svensson et al., 2003; Ranjan et al., 2006; Lykkesfeldt and Svendsen, 2007). Furthermore, previous studies have shown that preweaning neonatal calves experience higher OS than periparturient dairy cows (Abuelo et al., 2014). Hence, increasing our understanding of the implications of OS in neonatal health could lead to management practices that result in reduced morbidity and mortality rates in neonates via nutritional manipulation.

In the current study, calves exposed to high maternal OS during late gestation had significantly higher serum Hp and basal TNF- $\alpha$ concentration. These data suggest that prenatal exposure to elevated maternal OS is associated with an increased level of inflammation. Similar results were also reported in a recent human study where maternal lipid peroxides and malondialdehyde (a product of lipid oxidation) were positively associated with the expression of proinflammatory cytokines in the offspring (Hernández-Trejo et al., 2017). As oxidants are intrinsically involved in the activation of several inflammatory pathways (Mittal et al., 2014), the significantly higher plasma concentration of RONS in calves exposed to high maternal OS may contribute to their elevated level of basal inflammation. For example, RONS activates nuclear factor kappa B, which enhances inflammation by increasing the expression of proinflammatory cytokines (Blaser et al., 2016) and adhesion molecules (Mittal et al., 2014). Furthermore, RONS also activate mitogen-activated protein kinases pathways, which play an essential role in intracellular signaling pathways that are involved in the regulation of cellular activities during inflammation (Son et al., 2011). In vitro studies performed in bovine endothelial cells also demonstrate that OS-induced peroxidation is associated with an increased inflammatory phenotype in these cells (Weaver et al., 2001; Sordillo et al., 2008).

The clinical significance of elevated TNF- $\alpha$ and Hp concentrations during the first month of life is unknown. Further research is warranted to determine whether an elevated basal inflammatory status during this period is associated with adverse health and production outcomes. Murray et al. (2014) reported that serum Hp concentrations in dairy calves during the first week of life are positively associated with morbidity and mortality during the first 4 mo of life. Furthermore, elevated TNF- $\alpha$ concentrations contribute to impaired metabolic function in dairy cattle (McCarthy et al., 2016) and may adversely affect growth rates by inhibition of IGF-1 (Suda et al., 2003; Borghetti et al., 2009). The relationship between the amount of basal inflammation during the neonatal period and the development of dysregulated inflammatory responses later in life is also unknown. This is of particular interest because dysregulated inflammation in dairy cattle is highly implicated in the pathogenesis of metabolic stress during the transition period and inflammatory-based diseases, such as mastitis and endometritis (LeBlanc, 2014; Sordillo and Mavangira, 2014).

Differences in the cell-mediated innate immune response of the offspring associated with the lategestation maternal metabolic stress biomarkers were assessed by LPS stimulation of whole blood and subsequent cytokine analysis as described previously in experiments involving adult dairy cows (Røntved et al., 2005; O'Boyle et al., 2006). Compared with stimulation of peripheral blood mononuclear cells, measuring cytokines in whole blood has the advantage of preserving the physiological proportions of all natural components of the blood (Damsgaard et al., 2009). The main limitation, however, refers to the potential difference in the release of TNF- $\alpha$ in animals due to differences in the number of cells present in the peripheral blood, where mononuclear cells account for the bulk of TNF- $\alpha$ pro- 
duction. Nevertheless, we found no differences among groups in either total or differential cell counts (Table 4 ), and all the samples were within the reported reference intervals. Hence, we were able to rule out differences in TNF- $\alpha$ production due to different numbers of mononuclear cells in blood.

Successful immune activation depends upon a rapid increase in proinflammatory cytokine production (Watkins et al., 1995), such as TNF- $\alpha$. Likewise, the capacity to recover homeostasis following an acute inflammatory insult relies on a quick cytokine storm that is resolved promptly (Bradford et al., 2015). Hence, we expressed the release of TNF- $\alpha$ following LPS stimulation as the percentage increase from the basal concentration to reflect the signaling capacity of the immune cells against a microbial agonist. Prenatal exposure to higher maternal inflammation (assessed by serum Hp concentration) during late gestation was associated with a reduced LPS-stimulated TNF- $\alpha$ release during the first month of life (Table 7, Figure 2B). Studies in murine models also demonstrate that in utero programming of neonatal cell-mediated immunity is sensitive to maternal inflammation. For example, rats exposed to a proinflammatory stimulus during late gestation produced offspring with a significantly reduced TNF- $\alpha$ response to LPS stimulation (Hodyl et al., 2007, 2008; Beloosesky et al., 2010). Although it was beyond the scope of our study to investigate the clinical significance of these results, prenatal exposure to high maternal inflammation has been associated with increased risk of infectious disease in human neonates. For example, Morales et al. (2011) reported in humans that exposure to high maternal inflammation during gestation is positively associated with the development of wheeze and recurrent respiratory tract infections during the first 14 mo of life. Therefore, it is likely that metabolic stress in dairy cows during late gestation may also have a negative effect on the resistance of their offspring to infectious diseases.

Calves born to cows that experienced a higher degree of OS showed a higher TNF- $\alpha$ concentration following LPS stimulation but a significantly lower increase from the basal concentration, which could suggest a reduced signaling capacity in these animals associated with their higher proinflammatory status. This finding is compatible with research in periparturient dairy cattle, where sustained inflammation can result in an antiinflammatory response to prevent a cytokine storm and maintain homeostasis (Bradford et al., 2015). It is unknown, however, whether the diminished fold increase in TNF- $\alpha$ following LPS stimulation in calves born to high OS cows is a direct carryover effect of OS exposure during gestation due to the higher basal TNF- $\alpha$ concentration observed concurrently or to other physiologi- 
Table 8. Results of the LPS stimulation test based on the degree of maternal inflammatory status, presented by week of life [shown as the tumor necrosis factor- $\alpha$ plasma concentration $(\mathrm{LSM} \pm \mathrm{SE} ; \mathrm{ng} / \mathrm{mL} \text { ) after the stimulation with different concentrations of LPS }]^{1}$

\begin{tabular}{|c|c|c|c|c|c|c|c|c|}
\hline \multirow[b]{2}{*}{$\begin{array}{l}\text { LPS } \\
\text { stimulation }\end{array}$} & \multicolumn{2}{|c|}{ Wk 1} & \multicolumn{2}{|c|}{ Wk 2} & \multicolumn{2}{|c|}{ Wk 3} & \multicolumn{2}{|c|}{ Wk 4} \\
\hline & $\begin{array}{l}\text { Low Hp } \\
(\mathrm{n}=6)\end{array}$ & $\begin{array}{l}\text { High Hp } \\
(\mathrm{n}=6)\end{array}$ & $\begin{array}{l}\text { Low Hp } \\
(\mathrm{n}=6)\end{array}$ & $\begin{array}{l}\text { High Hp } \\
(\mathrm{n}=6)\end{array}$ & $\begin{array}{l}\text { Low Hp } \\
(\mathrm{n}=6)\end{array}$ & $\begin{array}{l}\text { High Hp } \\
(\mathrm{n}=6)\end{array}$ & $\begin{array}{l}\text { Low Hp } \\
(\mathrm{n}=6)\end{array}$ & $\begin{array}{l}\text { High Hp } \\
(\mathrm{n}=6)\end{array}$ \\
\hline Basal & $2.70 \pm 0.505$ & $1.39 \pm 0.146^{*}$ & $1.60 \pm 0.281$ & $1.57 \pm 0.460$ & $2.71 \pm 0.277$ & $1.40 \pm 0.228^{*}$ & $2.20 \pm 0.320$ & $1.27 \pm 0.218^{*}$ \\
\hline $\begin{array}{l}10 \mathrm{ng} / \mathrm{mL} \\
\text { of LPS }\end{array}$ & $3.75 \pm 0.317$ & $1.55 \pm 0.222^{*}$ & $2.39 \pm 0.245$ & $1.68 \pm 0.032^{*}$ & $3.34 \pm 0.694$ & $1.44 \pm 0.121^{*}$ & $2.76 \pm 0.174$ & $1.788 \pm 0.097^{*}$ \\
\hline $\begin{array}{c}5 \mu \mathrm{g} / \mathrm{mL} \\
\text { of LPS }\end{array}$ & $4.87 \pm 0.564$ & $3.13 \pm 0.475^{*}$ & $4.01 \pm 0.727$ & $4.02 \pm 0.670$ & $5.90 \pm 0.948$ & $5.90 \pm 1.310$ & $8.60 \pm 1.010$ & $4.93 \pm 0.592^{*}$ \\
\hline
\end{tabular}

cal mechanism not controlled for in our observational study. In periparturient dairy cows, it has been established that animals with a sustained proinflammatory status show a reduced capacity to mount an effective immune response (Sordillo and Raphael, 2013). Calves exposed to higher maternal OS also showed a significantly higher plasma concentration of RONS, which may have contributed further to the reduced TNF- $\alpha$ release observed in these calves. Increases in the concentration of RONS may cause immunosuppression as overproduction of free radicals compromise leukocyte function (Sordillo and Aitken, 2009).

The results of our study demonstrate that prenatal exposure to higher maternal inflammation and OS are associated with a reduced fold increase in TNF- $\alpha$ concentration after an ex vivo LPS stimulation. However, it is unknown whether the resulting differences in cell-mediated innate immune response in these calves is substantial enough to increase their risk of infectious disease. Cell-mediated immunity plays an essential role in the elimination of intracellular pathogens (Zhu and Paul, 2008), which are highly implicated in the etiology of diarrhea and respiratory disease (Ames, 1997; Svensson et al., 2003; Izzo et al., 2011). Furthermore, morbidity during the first 3 mo of life is associated with adverse health and production later in life (WaltnerToews et al., 1986; Warnick et al., 1997). Therefore, further research is warranted to determine whether prenatal exposure to high maternal inflammation and OS influences the offspring's disease susceptibility and future productivity.

Prenatal exposure to a higher degree of lipid mobilization and OS was associated with lower BW at birth and throughout the 4-wk study period. However, no association was identified between maternal metabolic stress and ADG at $4 \mathrm{wk}$ of age. These findings are in line with previous research investigating the effect of in utero heat stress exposure, where calves born to heatstressed cows showed compromised immune responses from birth to weaning and decreased weights at birth and weaning but similar weaning ADG as calves born to cooled calves (Tao et al., 2012). Tao et al. (2012) also observed no differences in weight or height between heat-stressed $(\mathrm{n}=9)$ and cooled $(\mathrm{n}=12)$ groups from 3 to 7 mo of age, thereby indicating an effect of maternal status of fetal growth that is compensated after weaning. Hence, it will be interesting to explore in a larger study setting the long-term implications of maternal metabolic stress during late gestation in terms of immune function, susceptibility to diseases, and growth rates.

We established for the first time that the degree of metabolic stress in dairy cows during late gestation is associated with differences in the immune and metabolic responses of their offspring in postnatal life. The LPS-stimulated TNF- $\alpha$ release is commonly used to assess cell-mediated innate immunity, as TNF- $\alpha$ is produced primarily by activated macrophages. This cytokine, however, can also be secreted by other cell types, such as lymphocytes, natural killer cells, or neutrophils, among others (Parkin and Cohen, 2001); hence, an implication of adaptive immunity in the results cannot be ruled out. Consequently, the findings of our study can only conclude that maternal metabolic stress during late gestation influences some aspects of the cell-mediated immunity of the offspring in postnatal life, but not which specific immune cells populations are affected. Similarly, due to the pilot nature of our study and the reduced sample size employed, other effects not identified here cannot be ruled out. Further studies with adequate sample sizes are required to quantify the effect of the differences observed in the calves' metabolic and immune responses in terms of susceptibility to diseases and growth performance. Is also important to note that the feeding regimen of the calves in our study, still more commonly used on Australian dairy farms (Dairy Australia, 2017), allows for significantly lower growth rates than those more intense regimens typically found 


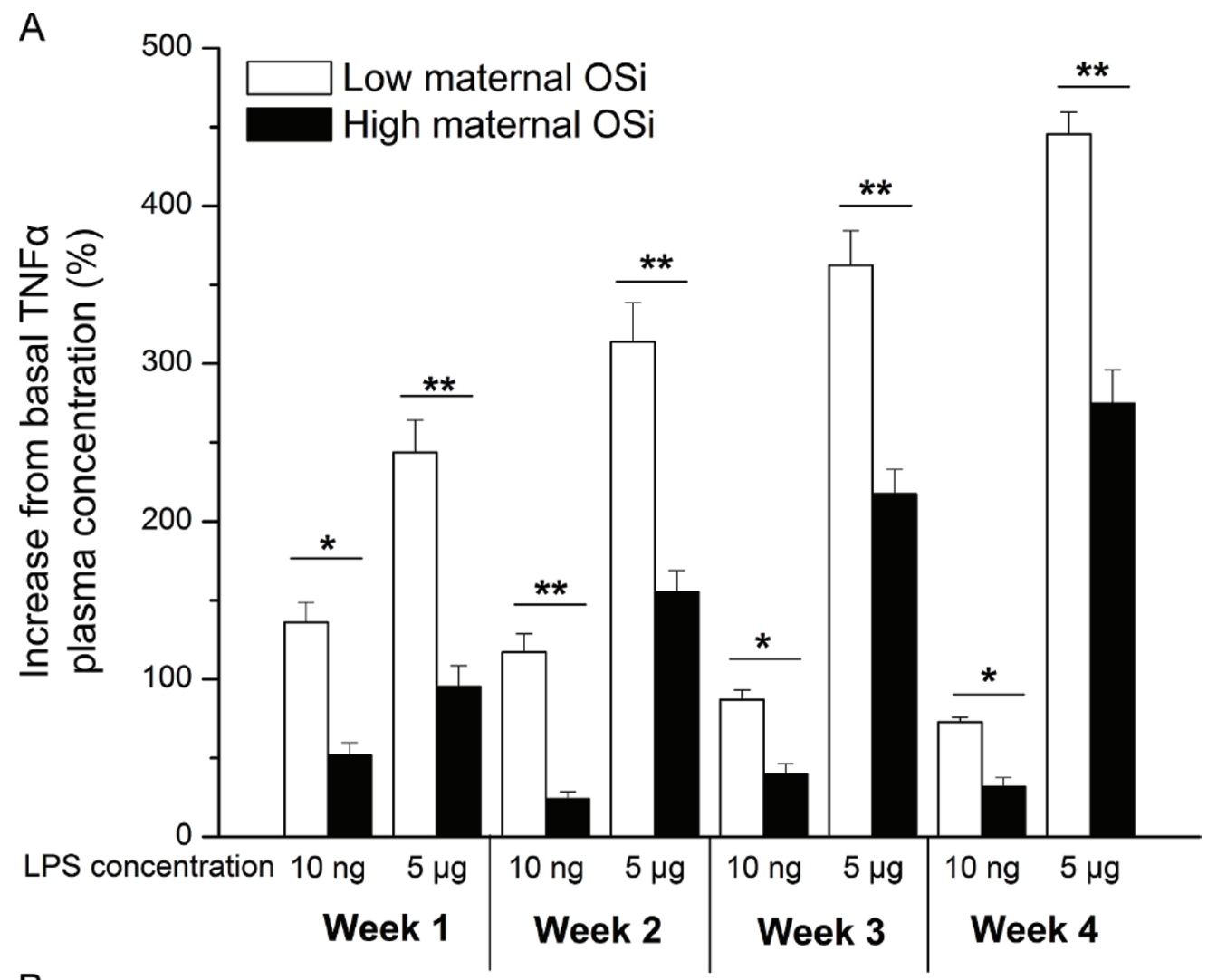

B

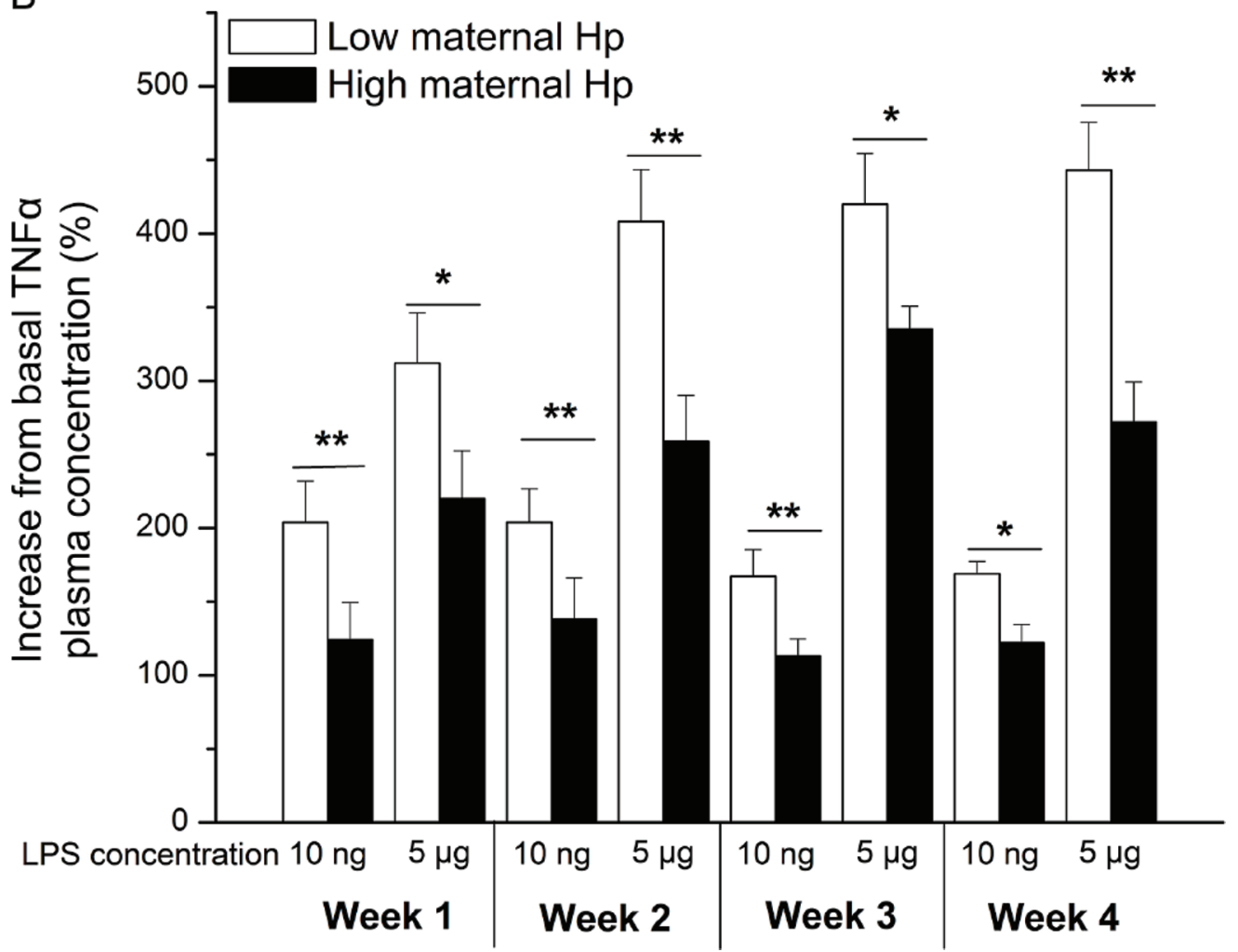

Figure 2. Tumor necrosis factor (TNF)- $\alpha$ response of calf blood cells to an ex vivo LPS stimulation test according to the degree of maternal (A) oxidant status or (B) inflammation during late gestation. Results expressed in percentage increase from basal concentration (LSM \pm SE). OSi $=$ oxidant status index; $\mathrm{Hp}=$ haptoglobin. ${ }^{*} P<0.05,{ }^{*} P<0.01$. 
in North America. Hence, further studies are needed to measure the effect of maternal metabolic stress on calves under these intense rearing systems.

\section{CONCLUSIONS}

The results of this study demonstrate that metabolic stress in dairy cows during late gestation was associated with differences in the immune and metabolic responses of the offspring during the first mo of life. A higher degree of exposure to the 3 components of the metabolic stress triad in utero was associated with conditions in calves (e.g., sustained proinflammatory status, reduced TNF- $\alpha$ release, increased oxidant status) linked to impaired health and production in adult cows. Hence, reducing metabolic stress during the dry period could potentially result in enhanced dairy cow health and productivity and also benefit calf health. Further research is required to determine the mechanisms by which metabolic stress during late gestation affects the immune and metabolic responses of the offspring and the clinical effect of these carryover effects on the health and growth of the offspring. This will allow the development of management practices that ultimately enhance the health and production of replacement heifers.

\section{ACKNOWLEDGMENTS}

The authors gratefully acknowledge Syd and Patricia Clarke for allowing us to perform the study on their farm. This study is part of the Bachelor of Veterinary Biology/Bachelor of Veterinary Science (Honours) dissertation of T. Ling. This work was supported financially by the award of an Honours scholarship by the Graham Centre for Agricultural Innovation (Wagga Wagga NSW, Australia) and the Darcy John O'Sullivan Bequest administered by Charles Sturt University. The funders played no role in the design of the study, collection, analysis, and interpretation of data, or preparation or approval of the manuscript.

\section{REFERENCES}

Abuelo, A., J. C. Gandy, L. Neuder, J. Brester, and L. M. Sordillo. 2016. Short communication: Markers of oxidant status and inflammation relative to the development of claw lesions associated with lameness in early lactation cows. J. Dairy Sci. 99:5640-5648.

Abuelo, A., J. Hernandez, J. L. Benedito, and C. Castillo. 2013. Oxidative stress index (OSi) as a new tool to assess redox status in dairy cattle during the transition period. Animal 7:1374-1378.

Abuelo, A., J. Hernandez, J. L. Benedito, and C. Castillo. 2015. The importance of the oxidative status of dairy cattle in the periparturient period: revisiting antioxidant supplementation. J. Anim. Physiol. Anim. Nutr. (Berl.) 99:1003-1016.
Abuelo, A., M. Perez-Santos, J. Hernandez, and C. Castillo. 2014. Effect of colostrum redox balance on the oxidative status of calves during the first 3 months of life and the relationship with passive immune acquisition. Vet. J. 199:295-299.

Ames, T. R. 1997. Dairy calf pneumonia. The disease and its impact. Vet. Clin. North Am. Food Anim. Pract. 13:379-391.

Beloosesky, R., N. Maravi, Z. Weiner, N. Khatib, N. Awad, J. Boles, M. G. Ross, and J. Itskovitz-Eldor. 2010. Maternal lipopolysaccharide-induced inflammation during pregnancy programs impaired offspring Innate immune responses. Am. J. Obstet. Gynecol. 203:185.e1-185.e4.

Blaser, H., C. Dostert, T. W. Mak, and D. Brenner. 2016. TNF and ROS crosstalk in inflammation. Trends Cell Biol. 26:249-261.

Borghetti, P., R. Saleri, E. Mocchegiani, A. Corradi, and P. Martelli. 2009. Infection, immunity and the neuroendocrine response. Vet. Immunol. Immunopathol. 130:141-162.

Bradford, B. J., K. Yuan, J. K. Farney, L. K. Mamedova, and A. J. Carpenter. 2015. Invited review: Inflammation during the transition to lactation: New adventures with an old flame. J. Dairy Sci. 98:6631-6650.

Dairy Australia. 2017. Rearing healthy calves. Dairy Australia Limited, Melbourne, Australia. Accessed Jun. 5, 2017. https://www .dairyaustralia.com.au/-/media/dairyaustralia/documents/farm/ animal-care/animal-welfare/calf-welfare/rearing-healthy-calves -manual-2nd-ed.ashx.

Damsgaard, C. T., L. Lauritzen, P. C. Calder, T. M. Kjaer, and H. Frokiaer. 2009. Whole-blood culture is a valid low-cost method to measure monocytic cytokines - a comparison of cytokine production in cultures of human whole-blood, mononuclear cells and monocytes. J. Immunol. Methods 340:95-101.

Edmonson, A. J., I. J. Lean, L. D. Weaver, T. Farver, and G. Webster. 1989. A body condition scoring chart for holstein dairy cows. J. Dairy Sci. 72:68-78.

Fowden, A. L., D. A. Giussani, and A. J. Forhead. 2006. Intrauterine programming of physiological systems: Causes and consequences. Physiology (Bethesda) 21:29-37.

Gao, F., Y. C. Liu, Z. H. Zhang, C. Z. Zhang, H. W. Su, and S. L. Li. 2012. Effect of prepartum maternal energy density on the growth performance, immunity, and antioxidation capability of neonatal calves. J. Dairy Sci. 95:4510-4518.

Godden, S. 2008. Colostrum management for dairy calves. Vet. Clin. North Am. Food Anim. Pract. 24:19-39.

Goff, J. P., and R. L. Horst. 1997. Physiological changes at parturition and their relationship to metabolic disorders. J. Dairy Sci. 80:1260-1268.

Grummer, R. R. 1993. Etiology of lipid-related metabolic disorders in periparturient dairy cows. J. Dairy Sci. 76:3882-3896.

Heinrichs, A. J., H. N. Erb, G. W. Rogers, J. B. Cooper, and C. M. Jones. 2007. Variability in Holstein heifer heart-girth measurements and comparison of prediction equations for live weight. Prev. Vet. Med. 78:333-338.

Hernández-Trejo, M., A. Montoya-Estrada, Y. Torres-Ramos, A. Espejel-Nunez, A. Guzman-Grenfell, R. Morales-Hernandez, M. Tolentino-Dolores, and E. Laresgoiti-Servitje. 2017. Oxidative stress biomarkers and their relationship with cytokine concentrations in overweight/obese pregnant women and their neonates. BMC Immunol. 18:3.

Higgins, D. A., M. J. Stack, and C. Richardson. 1983. Lymphocyte markers in the bovine foetus. Dev. Comp. Immunol. 7:369-377.

Hodyl, N. A., K. M. Krivanek, V. L. Clifton, and D. M. Hodgson. 2008. Innate immune dysfunction in the neonatal rat following prenatal endotoxin exposure. J. Neuroimmunol. 204:126-130.

Hodyl, N. A., K. M. Krivanek, E. Lawrence, V. L. Clifton, and D. M. Hodgson. 2007. Prenatal exposure to a pro-inflammatory stimulus causes delays in the development of the innate immune response to LPS in the offspring. J. Neuroimmunol. 190:61-71.

Inoguchi, T., P. Li, F. Umeda, H. Y. Yu, M. Kakimoto, M. Imamura, T. Aoki, T. Etoh, T. Hashimoto, M. Naruse, H. Sano, H. Utsumi, and H. Nawata. 2000. High glucose level and free fatty acid stimulate reactive oxygen species production through protein kinase $\mathrm{C}-$ 
dependent activation of $\mathrm{NAD}(\mathrm{P}) \mathrm{H}$ oxidase in cultured vascular cells. Diabetes 49:1939-1945.

Izzo, M. M., P. D. Kirkland, V. L. Mohler, N. R. Perkins, A. A. Gunn, and J. K. House. 2011. Prevalence of major enteric pathogens in Australian dairy calves with diarrhoea. Aust. Vet. J. 89:167-173.

Kehrli, M. E., Jr., B. J. Nonnecke, and J. A. Roth. 1989. Alterations in bovine neutrophil function during the periparturient period. Am. J. Vet. Res. 50:207-214.

LeBlanc, S. J. 2014. Reproductive tract inflammatory disease in postpartum dairy cows. Animal 8(Suppl. 1):54-63.

Listenberger, L. L., D. S. Ory, and J. E. Schaffer. 2001. Palmitate-induced apoptosis can occur through a ceramide-independent pathway. J. Biol. Chem. 276:14890-14895.

Lykkesfeldt, J., and O. Svendsen. 2007. Oxidants and antioxidants in disease: oxidative stress in farm animals. Vet. J. 173:502-511.

McCarthy, M. M., T. Yasui, M. J. Felippe, and T. R. Overton. 2016. Associations between the degree of early lactation inflammation and performance, metabolism, and immune function in dairy cows. J. Dairy Sci. 99:680-700.

McMillen, I. C., and J. S. Robinson. 2005. Developmental origins of the metabolic syndrome: Prediction, plasticity, and programming. Physiol. Rev. 85:571-633.

Merlot, E., D. Couret, and W. Otten. 2008. Prenatal stress, fetal imprinting and immunity. Brain Behav. Immun. 22:42-51.

Mittal, M., M. R. Siddiqui, K. Tran, S. P. Reddy, and A. B. Malik. 2014. Reactive oxygen species in inflammation and tissue injury. Antioxid. Redox Signal. 20:1126-1167.

Monteiro, A. P. A., S. Tao, I. M. T. Thompson, and G. E. Dahl. 2016. In utero heat stress decreases calf survival and performance through the first lactation. J. Dairy Sci. 99:8443-8450.

Morales, E., S. Guerra, R. Garcia-Esteban, M. Guxens, M. AlvarezPedrerol, M. Bustamante, X. Estivill, J. M. Anto, and J. Sunyer. 2011. Maternal C-reactive protein levels in pregnancy are associated with wheezing and lower respiratory tract infections in the offspring. Am. J. Obstet. Gynecol. 204:164.e161-9.

Murray, C. F., M. C. Windeyer, T. F. Duffield, D. B. Haley, D. L. Pearl, K. M. Waalderbos, and K. E. Leslie. 2014. Associations of serum haptoglobin in newborn dairy calves with health, growth, and mortality up to 4 months of age. J. Dairy Sci. 97:7844-7855.

Nonnecke, B. J., K. Kimura, J. P. Goff, and M. E. Kehrli Jr. 2003 Effects of the mammary gland on functional capacities of blood mononuclear leukocyte populations from periparturient cows. J. Dairy Sci. 86:2359-2368.

O'Boyle, N., C. M. Corl, J. C. Gandy, and L. M. Sordillo. 2006. Relationship of body condition score and oxidant stress to tumor necrosis factor expression in dairy cattle. Vet. Immunol. Immunopathol. 113:297-304.

Ohtsu, A., H. Tanaka, K. Seno, H. Iwata, T. Kuwayama, and K. Shirasuna. 2017. Palmitic acid stimulates interleukin-8 via the TLR4/ NF-kappaB/ROS pathway and induces mitochondrial dysfunction in bovine oviduct epithelial cells. Am. J. Reprod. Immunol. $77: \mathrm{e} 12642$

Osorio, J. S., E. Trevisi, M. A. Ballou, G. Bertoni, J. K. Drackley, and J. J. Loor. 2013. Effect of the level of maternal energy intake prepartum on immunometabolic markers, polymorphonuclear leukocyte function, and neutrophil gene network expression in neonatal Holstein heifer calves. J. Dairy Sci. 96:3573-3587.

Parkin, J., and B. Cohen. 2001. An overview of the immune system. Lancet 357:1777-1789.

Ranjan, R., R. Naresh, R. C. Patra, and D. Swarup. 2006. Erythrocyte lipid peroxides and blood zinc and copper concentrations in acute undifferentiated diarrhoea in calves. Vet. Res. Commun. 30:249-254.

Re, R., N. Pellegrini, A. Proteggente, A. Pannala, M. Yang, and C. Rice-Evans. 1999. Antioxidant activity applying an improved ABTS radical cation decolorization assay. Free Radic. Biol. Med. 26:1231-1237
Røntved, C. M., J. B. Andersen, J. Dernfalk, and K. L. Ingvartsen. 2005. Effects of diet energy density and milking frequency in early lactation on tumor necrosis factor-alpha responsiveness in dairy cows. Vet. Immunol. Immunopathol. 104:171-181.

Son, Y., Y. K. Cheong, N. H. Kim, H. T. Chung, D. G. Kang, and H. O. Pae. 2011. Mitogen-activated protein kinases and reactive oxygen species: How can ROS activate MAPK pathways? J. Signal Transduct. 2011:792639.

Sordillo, L. M., and S. L. Aitken. 2009. Impact of oxidative stress on the health and immune function of dairy cattle. Vet. Immunol. Immunopathol. 128:104-109.

Sordillo, L. M., and V. Mavangira. 2014. The nexus between nutrient metabolism, oxidative stress and inflammation in transition cows. Anim. Prod. Sci. 54:1204-1214.

Sordillo, L. M., and W. Raphael. 2013. Significance of metabolic stress, lipid mobilization, and inflammation on transition cow disorders. Vet. Clin. North Am. Food Anim. Pract. 29:267-278.

Sordillo, L. M., K. L. Streicher, I. K. Mullarky, J. C. Gandy, W. Trigona, and C. M. Corl. 2008. Selenium inhibits 15-hydroperoxyoctadecadienoic acid-induced intracellular adhesion molecule expression in aortic endothelial cells. Free Radic. Biol. Med. 44:34-43.

Suda, Y., K. Nagaoka, K. Nakagawa, T. Chiba, F. Yusa, H. Shinohara, A. Nihei, and T. Yamagishi. 2003. Change of plasma insulin-like growth factor-1 (IGF-1) concentration with early growth in Japanese beef cattle. Anim. Sci. J. 74:205-210.

Svensson, C., K. Lundborg, U. Emanuelson, and S. O. Olsson. 2003. Morbidity in Swedish dairy calves from birth to 90 days of age and individual calf-level risk factors for infectious diseases. Prev. Vet. Med. 58:179-197.

Tao, S., A. P. Monteiro, M. J. Hayen, and G. E. Dahl. 2014. Short communication: Maternal heat stress during the dry period alters postnatal whole-body insulin response of calves. J. Dairy Sci. 97:897-901.

Tao, S., A. P. Monteiro, I. M. Thompson, M. J. Hayen, and G. E Dahl. 2012. Effect of late-gestation maternal heat stress on growth and immune function of dairy calves. J. Dairy Sci. 95:7128-7136.

Van Hoeck, V., J. L. Leroy, M. Arias Alvarez, D. Rizos, A. GutierrezAdan, K. Schnorbusch, P. E. Bols, H. J. Leese, and R. G. Sturmey. 2013. Oocyte developmental failure in response to elevated nonesterified fatty acid concentrations: mechanistic insights. Reproduction 145:33-44.

Van Hoeck, V., D. Rizos, A. Gutierrez-Adan, I. Pintelon, E. Jorssen, I. Dufort, M. A. Sirard, A. Verlaet, N. Hermans, P. E. Bols, and J. L. Leroy. 2015. Interaction between differential gene expression profile and phenotype in bovine blastocysts originating from oocytes exposed to elevated non-esterified fatty acid concentrations. Reprod. Fertil. Dev. 27:372-384.

Waltner-Toews, D., S. W. Martin, and A. H. Meek. 1986. The effect of early calfhood health status on survivorship and age at first calving. Can. J. Vet. Res. 50:314-317.

Warnick, L. D., H. N. Erb, and M. E. White. 1997. The relationship of calfhood morbidity with survival after calving in 25 New York Holstein herds. Prev. Vet. Med. 31:263-273.

Watkins, L. R., S. F. Maier, and L. E. Goehler. 1995. Immune activation: The role of pro-inflammatory cytokines in inflammation, illness responses and pathological pain states. Pain 63:289-302.

Weaver, J. A., J. F. Maddox, Y. Z. Cao, I. K. Mullarky, and L. M. Sordillo. 2001. Increased 15-HPETE production decreases prostacyclin synthase activity during oxidant stress in aortic endothelial cells. Free Radic. Biol. Med. 30:299-308.

Windeyer, M. C., K. E. Leslie, S. M. Godden, D. C. Hodgins, K. D. Lissemore, and S. J. LeBlanc. 2014. Factors associated with morbidity, mortality, and growth of dairy heifer calves up to 3 months of age. Prev. Vet. Med. 113:231-240.

Zhu, J., and W. E. Paul. 2008. CD4 T cells: Fates, functions, and faults. Blood 112:1557-1569. 